\title{
Right Ethmoidal Sinus Schwannoma: Case Report of a Common Entity with an Unusual Presentation
}

\author{
E.M. Kavitha ${ }^{1}$, L. Swapna ${ }^{1}$, B.N. Kumarguru ${ }^{1 *}$, S. Kranthi Kumar², M.Udaya Kumar ${ }^{1}$ \\ ${ }^{1}$ Department of Pathology, PES Institute of Medical Sciences and Research [PESIMSR], INDIA \\ ${ }^{2}$ Department of Neurosurgery, PES Institute of Medical Sciences and Research [PESIMSR] INDIA
}

\begin{abstract}
Schwannomas are benign, encapsulated nerve sheath tumors arising from Schwann cells. Approximately, 25-40\% of all Schwannomas occur in the head and neck region, acoustic nerve being the most frequent site. The tumors originating from nasal cavity or paranasal sinuses are rare and constitutes only four percent.

A 40-year-old male presented with history of blurred vision of right eye and protrusion of right eye ball since 6 months. It was associated with history of watering and redness. Examination of right eye revealed mild proptosis and ptosis. Computed Tomography [CT] scan showed a large expansile cystic lesion measuring about $5.2 \times 5.6 \times 6.5 \mathrm{~cm}$ involving entire right ethmoidal sinus. It showed expansion into anterior cranial fossa, roof and medial wall of right orbit. Radiological opinion suggested mucocele of right ethmoidal sinus. Intra-operatively, tissue specimen was sent for squash smear cytology. Cytology smears showed features suggestive of spindle cell tumor. Possibility of Schwannoma was considered. The specimen was subsequently subjected to histopathological examination. Microscopy showed tumor tissue composed of tumor cells arranged in alternate hypercellular and hypocellular pattern. Hypercellular areas showed occasional verocay bodies. Hypocellular areas showed loosely arranged spindle shaped tumor cells. Histopathological features were suggestive of Schwannoma. On Immunohistochemistry (IHC), neoplastic cells were positive for S-100 and negative for EMA.

Ethmoidal sinus schwannoma extending into anterior cranial fossa is an unusual presentation. Clinically, it poses a diagnostic dilemma. Squash smear cytology is challenging, but helpful in establishing the correct diagnosis. Histopathology is confirmatory and immunohistochemistry is supportive.
\end{abstract}

Keywords: Tumors, Cytology, Microscopy, Immunohistochemistry

\section{Introduction}

Schwannoma is a benign encapsulated nerve sheath tumor composed of entirely well-differentiated Schwann cells. ${ }^{[1,2]}$ This entity was first described by Verocay in 1908. Stout coined the term neurilemmoma. Most frequently, the neoplasm originates from acoustic nerve ${ }^{[2]}$ Approximately $25-40 \%$ of Schwannomas occur in head and neck region. Only four percent of head and neck Schwanommas are reported to arise in sinonasal cavity. ${ }^{[3]}$ The neoplasm may affect patient of any age group and has no particular sex predilection. ${ }^{[1,3]}$ We hereby report a case of right ethmoidal sinus Schwanomma with intracranial extension in a 40 year old male patient.

\section{Case Report}

A 40 year old male presented with history of blurred vision of right eye and protrusion of right eye ball since 6 months. It was associated with history of watering and redness. There was past history of trauma to the right eye prior to the development of symptoms. Ophthalmologic examination of right eye revealed mild proptosis and ptosis. It was associated with superior and medial rectus palsy. Computed Tomography (CT) scan of paranasal sinuses (PNS) was done and showed a large expansile cystic lesion measuring about $5.2 \times 5.6 \times 6.5 \mathrm{~cm}$ involving the entire right ethmoidal sinus. The lesion was seen as hypodense area with a focal hyperdense area. It showed expansion of the lesion into anterior cranial fossa, roof and medial wall of right orbit. The bony margins were thin with areas of breakdown. Magnetic Resonance Imaging (MRI) showed right ethmoidal sinus hyperintense mass lesion with intracranial extension. (Fig.1) Radiological opinion suggested mucocoele of right ethmoidal sinus. However, differential diagnosis of aneurysmal bone cyst (ABC) was also offered. The patient underwent craniotomy with excision of the lesion. Intra-operatively, tissue specimen was sent for squash smear cytology. Cytology smears were cellular and showed tumor cells arranged in clusters and fascicles. Some of the clusters of tumor cells showed frayed rope appearance. At places, interlacing bundles of filaments showed right angled criss-crossing. Individual tumor cells were spindle shaped cells having moderate amount of cytoplasm and vesicular to hyperchromatic nucleus. 
Some of the tumor cells showed nuclear pleomorphism and nuclear streaking. Background showed proteinaceous material and few erythrocytes. Squash smear features were suggestive of benign spindle cell tumor. Based on constellation of cytological findings, possibility of schwannoma was considered. (Fig.2) The rest of the tissue specimen was preserved in $10 \%$ buffered formalin and was subjected to histopathological examination. Microscopy showed a partially encapsulated lesional tissue composed of tumor cells displaying alternate hypercellular (Antoni A) and hypocellular (Antoni B) areas. Hypercellular areas showed occasional verocay bodies. Hypocellular areas showed loosely arranged spindle shaped tumor cells. Individual tumor cells were spindle shaped cells having moderate amount of eosinophilic cytoplasm and mildy hyperchromatic nucleus. Also seen were foci of haemorrhage and thickened, hyalinized and sclerosed blood vessels. At places, tumor tissue was seen encroaching the brain tissue. Histopathological features were suggestive of schwannoma with evidence of intracranial extension. (Fig.3) Immunohistochemistry (IHC) of tumor tissue was performed. The neoplastic cells were positive for S-100 and negative for Epithelial Membrane Antigen (EMA). IHC supported the histopathological diagnosis. (Fig.3) Post-operative period was unevenful. The patient was discharged in a stable condition.
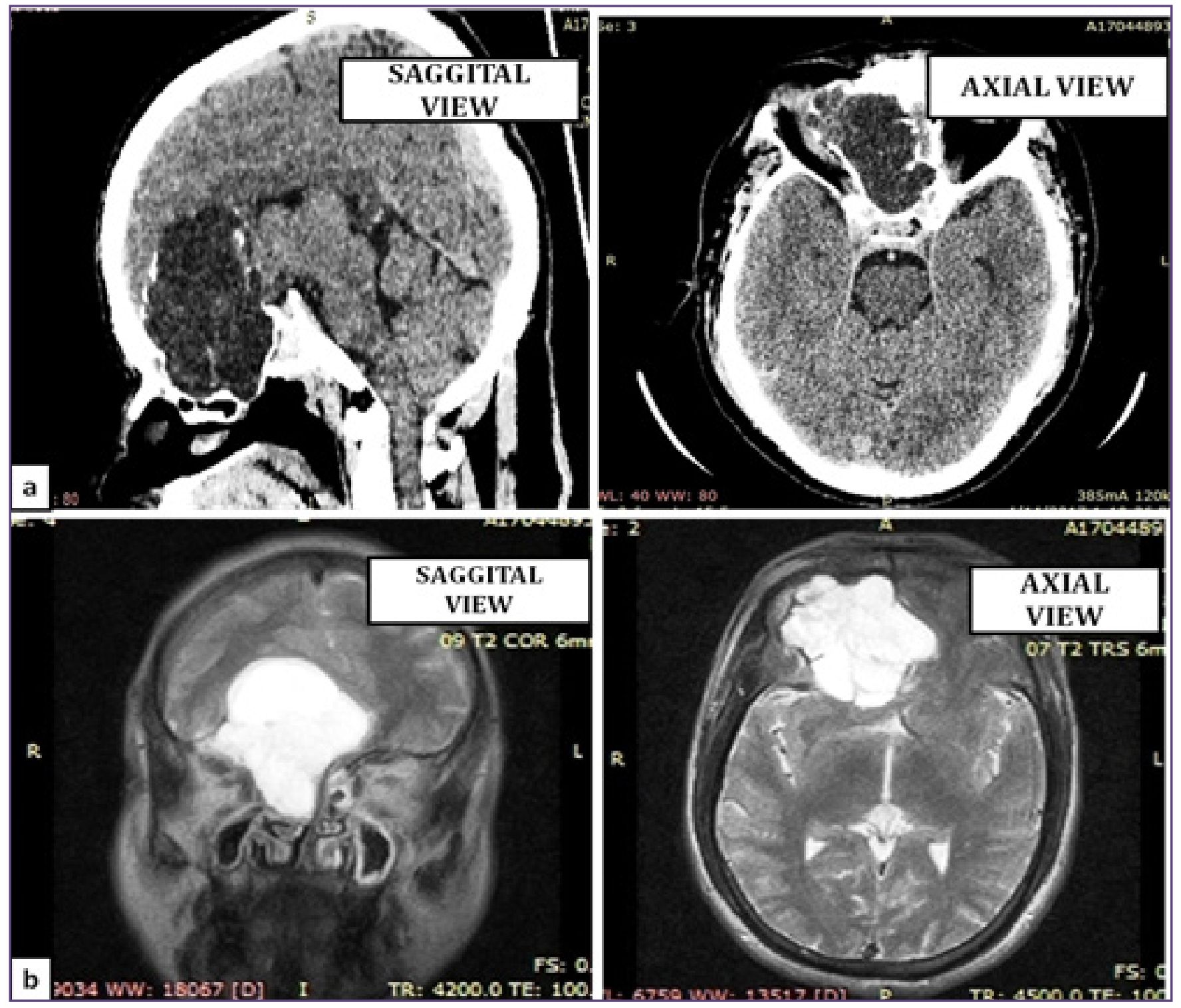

Fig. 1a-b:(a)CT scan image of paranasal sinuses show right ethmoidal sinus hypodense mass lesion with intracranial extension. (b) MRI of paranasal sinuses show right ethmoidal sinus hyperintense mass lesion with intracranial extension. 


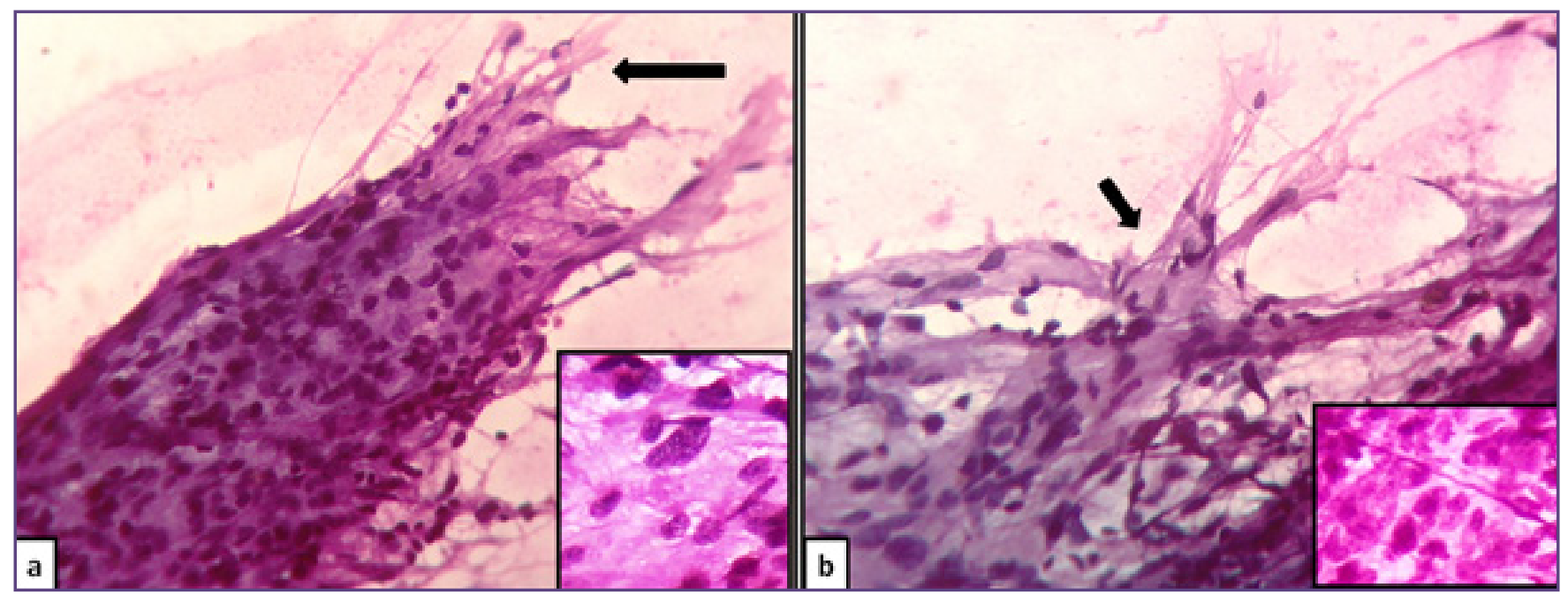

Fig. 2a-b:(a) Squash smear: Spindle shaped tumor cells arranged in clusters displaying frayed rope appearance (Arrow) [X400, PAP]. Inset: Nuclear pleomorphism.(b)Interlacing bundles of filaments show right angled crisscrossing (Arrow) [X400, PAP]. Inset: Nuclear streaking.

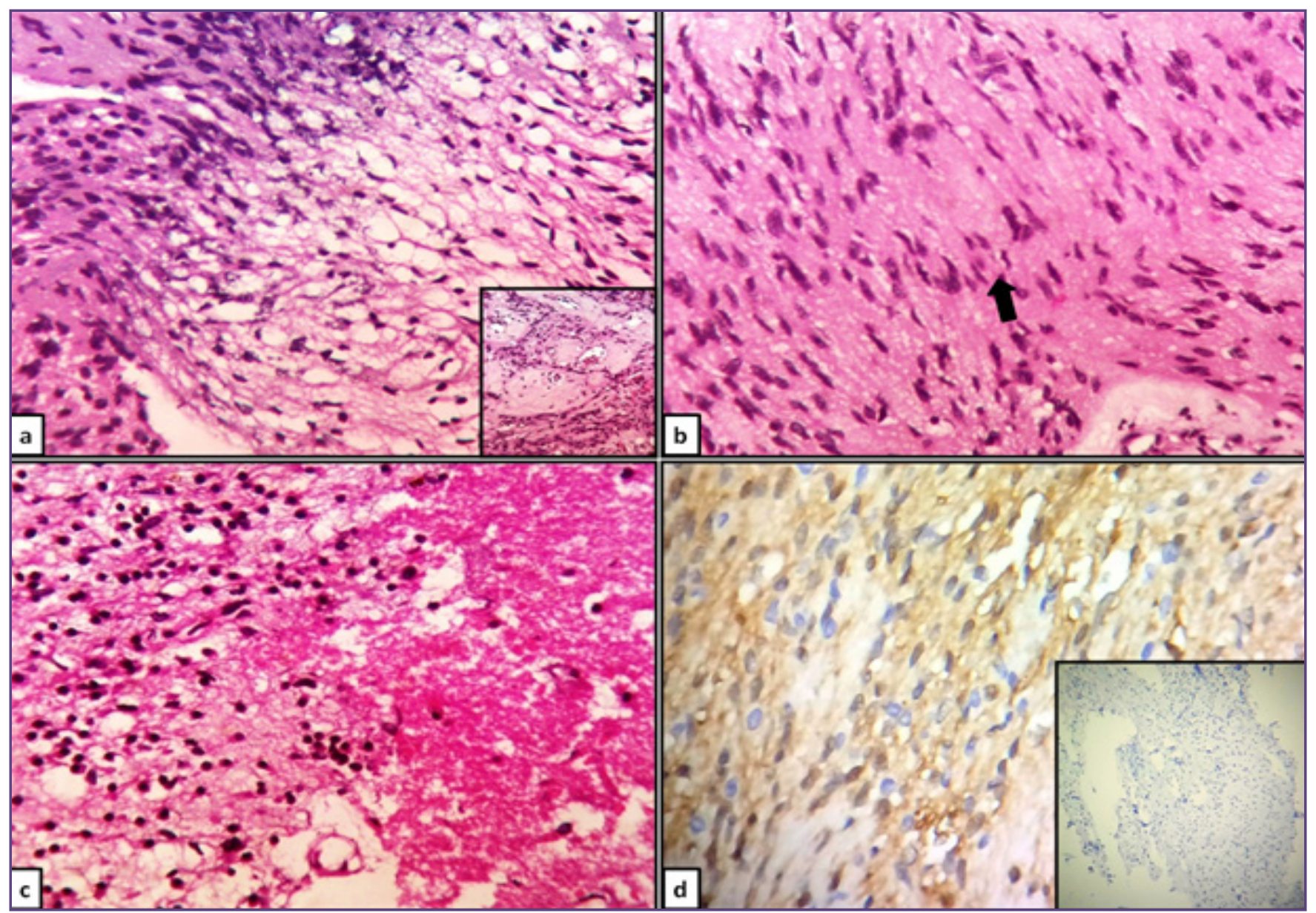

Fig. 3a-d:(a) Histopathology: Tumor tissue displaying alternate hypercellular (Antoni-A) area and hypocellular (Antoni-B) area.[X400,H\&E]. Inset: Sclerosed blood vessels. (b) Verocay body (Arrow).[X400,H\&E]. (c) Tumor tissue encroaching brain parenchyma.[X400,H\&E]. (d) IHC-Neoplastic cells positive for S-100. Inset: Neoplastic cells negative for EMA.[X400,IHC]. 


\section{Discussion}

Schwannomas are benign slow growing nerve sheath tumors that arise from schwann cells, derived from the neuroectoderm. ${ }^{[4,5]}$ Solitary schwannoma is also called as neurilemmoma, neurolemmoma, perineural fibroblastoma and neurinoma. ${ }^{[2,5]}$

Schwannommas may be encountered at any age. Peak incidence is in fourth to sixth decade. ${ }^{[1,3]}$ Most studies show no sex or racial predeliction. ${ }^{[2,3]}$ In the present case, the lesion was seen in a male patient in the fifth decade. Mitra $\mathrm{B}$ et $\mathrm{al}^{[2]}$ described a case of schwannoma in third decade. Vaidya MM et al ${ }^{[3]}$, Dhawle MS et al ${ }^{[4]}$, Mangubat EZ et a ${ }^{[6]}$, Mosalleum $\mathrm{EMA}^{[7]}$ et al documented the tumor in fourth decade. Singh $\mathrm{M}$ et al ${ }^{[5]}$ observed the lesion in fifth decade. Wong $\mathrm{E}$ et $\mathrm{al}^{[8]}$ reported a case of sinonasal schwannoma in sixth decade in their case report. Mitra B et a ${ }^{[2]}$, Vaidya MM et al ${ }^{[3]}$, Dhawle MS et $\mathrm{a}^{\left[{ }^{[4]}\right.}$ and Mangubat EZ et al ${ }^{[6]}$ documented schwannoma in male patient. On the contrary, Singh $\mathrm{M}$ et $\mathrm{al}^{[5]}$, Mosalleum $\mathrm{EMA}^{[7]}$ and Wong $\mathrm{E}$ et al ${ }^{[8]}$ reported the lesion in female patients in their case reports.

In the present case, Schwannoma was arising from right ethmoid sinus and was seen extend into the anterial cranial fossa. Vaidya $\mathrm{MM}$ et $\mathrm{al}^{\left[{ }^{[3]}\right.}$ also reported a case of Schwanomma arising from right ethmoidal sinus with similar presentation (intracranial extension into anterior cranial fossa). Dhawle MS et $\mathrm{al}^{[4]}$ documented the tumor arising from right maxillary sinus. Singh $\mathrm{M}$ et al ${ }^{[5]}$ reported the lesion involving the right ethmoidal sinus, maxillary sinus and bilateral sphenoidal sinuses. Mangubat EZ et $\mathrm{al}^{[6]}$ described a case of schwannoma presenting as right frontal sinus lesion. Wong $\mathrm{E}$ et $\mathrm{al}^{[8]}$ reported a case of giant primary schannoma involving left nasal cavity and ethmoidal sinus. In contrast, Mosalleum $\mathrm{EMA}^{[7]}$ et al documented the neoplasm involving left nasal vestibule without any involvement of paranasal sinues. Mitra B et $\mathrm{al}^{[2]}$ also described a case of schwannoma arising from left side of nasal septum without involving paranasal sinuses.

In the present case, radiological diagnosed offered was mucocele. However possibility of auerysmal bone cyst $(\mathrm{ABC})$ was suggested. Clinical and radiological differential diagnosis for sinonasal mass includes mucocele, polyp, angiofibroma, inverted papilloma, melanoma, squamous cell carcinoma, adenocarcinoma, sarcoma, lymphoma, aesthesioneuroblastoma, meningioma, intraosseous cavernous hemangioma and aggressive fungal infection. This is because of non-specific imaging features of schwannoma. ${ }^{[6]}$

Histopathological differential diagnosis includes neurofibroma, meningioma, angifibroma, glomangiopericytoma and leiomyoma. Neurofibroma is a benign peripheral nerve tumor composed of Schwann cells, perineural cells and intra-neural fibroblast ${ }^{[7]}$ Residual axons are often present within the tumor. Unlike, Schwannoma, blood vessels in neurofibroma generally lack hyalinization. ${ }^{[1]}$ Ectopic or secondary meninigiomas of sinonasal cavity are mainly meningithelial or transitional type and rarely of fibroblastic variant. The tumors have a syncytial arrangement with a whorled pattern. Angiofibroma has characteristic hyalized vascula stroma containing stellate and spindled myofibroblasts with numerous mast cells. Glomangiopericytoma is a distintive spindle cell tumor originating from modified perivascular myoid cells. It is characterized by uniform spindle to oval cells and staghorn capillaries vessels. Leiomyomas show intersecting fascicles of spindled cells. The cells have cigar-shaped nuclei and perinuclear halo ${ }^{[7]}$ In contrast to other lesion, Schwannoma shows characteristic histopathological features. ${ }^{[4]}$

Neurofibromas are positive for S-100, EMA and NF. Immunoreactivity for EMA in meningioma can be helpful to exclude the diagnosis. Tumor cells of angiofibroma are reactive to vimentin and $\beta$-catenin and focal SMA. Glomangiopericytoma show immunoreactivity to SMA, FXIIIa and vimentin. In contrast to other tumors, Schwannomas are positive for S-100, LEU7, SOX10 \& calretinin and negative for EMA..$^{[1,4,7]}$ Loss of merlin (NF2 gene product) expression is is seen in conventional Schwannomma.

The neural origin of the schwannoma is considered to be arising from peripheral motor, sensory, sympathetic and cranial nerve sheath. The optic and olfactory nerves are not the potential sites of the origin, since they lack sheaths that contain schwann cells. ${ }^{[2]}$ Sinonasal schwannomas are postulated to be arising from sheath of the ophthalmic and maxillary branches of the trigeminal nerve or autonomic nerves to the septal vessels and mucosa. ${ }^{[9]}$ The ethmoidal sinus is the most commonly involved, followed by maxillary sinus, nasal fossa and sphenoidal sinus. ${ }^{[2]}$ KimYS et al ${ }^{[9]}$ hypothesized that Schwannoma occur more frequently in the nasal cavity and ethmoidal sinuses than in other paranasal sinuses because of their abundant and complex nerve innervations. Most Schwanommas do not present with referable neurological symptoms. It is therefore difficult to know the exact incidence of Schwanomma according to the nerve origin in the sinonasal cavity. ${ }^{[9]}$ Schwannommas very rarely undergo malignant change. Recurrences are more common for cellular schwannomas of intracranial, spinal and sacral regions.

\section{Conclusion}

Ethmoidal sinus Schwannoma extending into the anterior cranial fossa is an unusual presentation. Clinically, it 
poses a diagnostic dilemma. Squash smear cytology is challenging, buthelpful in establishing the correct diagnosis. Histopathology is confirmatory and immunohistochemistry provides supportive evidence.

\section{Acknowledgments}

We sincerely thank Department of Radiodiagnosis and Sumukh Histopath Lab for the kind cooperation extended to us for the work up of the case.

\section{Funding}

Nil

\section{Conflict of Interest}

None

\section{References}

1. Louis DN, Ohgaki H, Wiestler OD, Cavenee WK.WHO Classification of Tumors of the Central Nervous System. 4th ed.Lyon, France: IARC Press;2016.p214-221.

2. Mitra B, Debnath S, Paul B, Pal M, Banerjee TJ, Saha TN. Schwannoma of nasal septum: A rare case report with review of literature. Egyptian Journal of Ear, Nose, Throat and Allied Sciences 2012;13:121-5.
3. Vaidya MM, Shenoy AS, Goel NA. A Rare Case of Paranasal Sinus Schwannoma with Intracranial Extension. J Clin Diagn Res 2019;13:ED08-09.

4. Dhawle MS, Rathod SG, Bhatkule MA, Bindu RS. Sinonasal Schwannoma -A Case Report. J Clin Diagn Res 2017;11:ED22-23.

5. Singh M, Bhagat S, Sharma DK, Monga R, Chhabra $\mathrm{N}$. A large sinonasal schwannoma: a rare entity. Int J Otorhinolaryngol Head Neck Surg 2017;3:1126-9.

6. Mangubat EZ, Pitelka L, Petruzzelli GJ, Byrne RW. Frontal Sinus Schwannoma: Case Report and Review of Literature. Skull Base Rep 2011;1:17-22.

7. Mosalleum EMA, Phillips VM. Schwannoma of the nasal cavity: A case report and a review. Sudan Med Monit 2015;10:27-30.

8. Wong E, Kong J, Oh L, Cox D, Forer M. Giant Primary Schwannoma of the Left Nasal Cavity and Ethmoid Sinus. Case Reports in Otolaryngology 2016 Article ID 1706915 http://dx.doi.org/10.1155/2016/1706915.

9. Kim YS, Kim HJ. Kim CH, Kim J. CT and MR Imaging Finding of Sinonasal Schwannoma: A Review of 12 Cases.

*Corresponding author:

Dr. Kumarguru B.N, ‘Sri’nivasa, No: 204, 9th cross, BEML Layout, I stage, Basaveshwaranagara, Bangalore- 560079. Karnataka, India

Phone: +919845813257

Email: kumarguru1978@yahoo.com 